\title{
Supporting Foster and Kinship Carers to Promote the Mental Health of Children
}

Josh Fergeus - Department of Social Work, University of Melbourne

For correspondence:

University of Melbourne, Department of Social Work, Parkville, VIC, 3010

0466465421

j.fergeus@student.unimelb.edu.au

Cathy Humphreys - Professor of Social Work, Department of Social Work, The University of

Melbourne

Carol Harvey - Professor of Psychiatry, Department of Psychiatry, The University of Melbourne and North Western Mental Health, Melbourne has not been through the copyediting, typesetting, pagination and proofreading process, which

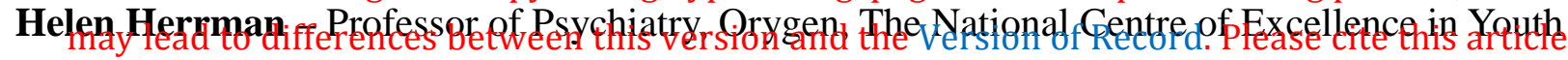
Mental Health; and Centre for Youth Mental Health, The University of Melbourne

This article is protected by copyright. All rights reserved. 


\section{Supporting Foster and Kinship Carers to Promote the Mental Health of Children}

Josh Fergeus - Department of Social Work, University of Melbourne

For correspondence:

University of Melbourne, Department of Social Work, Parkville, VIC, 3010

0466465421

j.fergeus@student.unimelb.edu.au

Cathy Humphreys - Professor of Social Work, Department of Social Work, The University of Melbourne

Carol Harvey - Professor of Psychiatry, Department of Psychiatry, The University of Melbourne and North Western Mental Health, Melbourne 
Helen Herrman - Professor of Psychiatry, Orygen, The National Centre of Excellence in Youth Mental Health; and Centre for Youth Mental Health, The University of Melbourne

\begin{abstract}
The majority of children and young people removed from the care of their parents by the State of Victoria, Australia, reside in foster or kinship care. These children have experienced a broad range of adverse conditions, and are up to four times more likely to experience problems with mental health than their mainstream peers. This paper draws on the perspectives of foster and kinship carers, describing the disconnection between their role as mental health advocates and their interest in early intervention in a field which is dominated by crisis and the historic marginalisation of foster and kinship carers. Thirty-one foster and kinship carers across greater metropolitan Melbourne, Australia, contributed to this study through interviews and focus groups. Participants demonstrated a practical understanding of mental health and an ability to identify a range of conditions that have an adverse impact on the mental health of children and young people in their care. The paper concludes that there is a lack of systemic support and even a range of barriers that affect the capacity of foster and kinship carers to promote the mental health and wellbeing of the children and young people in their care.
\end{abstract}

\title{
Keywords
}

Foster care; kinship care; mental health; carers; looked-after children; out-of-home care

\section{Background}

This paper draws on the perspectives of foster and kinship carers to examine their relationship with the mental health of children and young people in their care. It points to the disconnection between their role as mental health advocates and their interest in early intervention in a field which is dominated by crisis and the historic marginalisation of foster and kinship carers in out-of-home care services. In this paper, foster care is understood as the temporary care of children by accredited voluntary carers, while kinship care is the care provided by relatives or a member of a child's social 
network when a child cannot live with their parents. In Victoria, Australia, foster care and some kinship care services are delivered by community service organisations, commissioned by the Department of Health and Human Services, which regulates and oversees the out-of-home care system.

Mental health is the foundation for wellbeing and effective functioning for an individual and for a community (Herrman et al, 2005). It is "a state of wellbeing in which the individual realises his or her own abilities, can cope with the normal stresses of life, can work productively and fruitfully, and is able to make a contribution to his or her community" (World Health Organisation, 2016). Conversely, mental illness may cause considerable suffering or hinder an individual's ability to care for themselves and function effectively in day-to-day life. In addition to genetic predisposition, adverse conditions such as poverty, low levels of education, unemployment, exposure to conflict, social marginalisation and displacement are likely to compromise mental health and cause serious risk of mental illness (Herrman et al, 2005).

The greatest opportunity to prevent mental illness and provide effective early intervention to minimise its impact - which may otherwise have profound, long-term consequences - occurs during childhood. A lack of treatment in childhood may significantly increase the social and economic costs to the individual and the state later in life, a fact which has been recognised by both the Australian and Victorian Governments (Department of Health, 2011; Department of Health and Human Services, 2017). Such early intervention should include the identification of infants or children at higher risk of developing mental illness or severe behavioural and developmental disturbances, and the targeted promotion of mental health among these groups, including those in foster and kinship care.

Children in foster and kinship care are more likely to experience mental health problems than their mainstream peers (Fergeus et al, 2017). Children in out-of-home care in Australia are likely to have experienced a broad range of adverse conditions, and are up to four times more likely to experience problems with mental health than their mainstream peers (Milburn et al, 2008). Further, TarrenSweeney and Vetere (2013) claim that more than half of such children in the developed world have a measurable need for mental health services. The World Health Organisation argues that promoting mental health needs to be assigned a higher priority in vulnerable groups (Herrman et al, 2005). 
Given their level of vulnerability, the promotion of mental health amongst children in foster and kinship care should therefore be of the highest priority.

Foster and kinship carers provide a critical role in the lives of children in care. The knowledge, skills and resources possessed by carers can be pivotal in connecting youth to appropriate mental health services (Farmer et al, 2001). Conversely, Tarren-Sweeney (2010) found that carers without the requisite knowledge, skills or interest could be a barrier to accessing critical mental health services. Supportive relationships, such as those provided by foster and kinship carers, are considered to be a key determinant of children's mental health (Walker et al, 2005), and in recent years, there has been significant progress in identifying interventions that improve the ability of foster carers to respond to the mental health needs of children in their care (Fergeus et al, 2017).

When it comes to children in care, carers have emerged as powerful drivers of access to various forms of health care in a number of studies, and they can be an important agent of change when it comes to improving their child's emotional well-being, due to their expertise in understanding the individual child (Fergeus et al, 2017; Minnis \& Del Priore, 2001). Given that the uptake of mental health services for children in care is relatively low (York \& Jones, 2017), this represents a critical contribution. The quality of day-to-day care that children receive from foster and kinship carers and the nature of the caring environment are major factors influencing their mental health and wellbeing. Carers are likely to be the key to effective mental health promotion among children and young people in foster and kinship care. They may support increased social connectedness and the development of problem-solving skills, nurturing and providing empathetic care, and are key to lessening the impact of the multiple risk factors which can affect children in care (Development Services Group, 2015). It is therefore important to better understand carers' role in mental health promotion, their perspectives on mental health, and the support they receive in promoting mental health through their role in providing therapeutic caring environments for children and young people. This paper will examine two key questions:

- $\quad$ what is the role of the carer in promoting the mental health of vulnerable children in foster and kinship care?

- how can carers be supported to fulfil this role? 


\section{Method and Theoretical Framework}

This study was undertaken as part of the Ripple Project, a five-year National Health and Medical Research Council (NHMRC) funded study of approaches to improving the mental health of young people in out-of-home care. The study utilised thematic analysis to develop an understanding of the role of the carer in promoting the mental health of children and young people in foster and kinship care. To this end, the study design incorporates the use of semi-structured interviews and focus groups with foster and kinship carers providing care to children across Victoria.

\section{Ethics}

The study received primary ethics approval from the University of Melbourne Behavioural and Social Sciences Human Ethics Sub-Committtee. Additional approval was provided by the Department of Human Services Research Coordinating Committee, and the relevant committees of participating community service organisations. Participants opted in to participation in the study, and were free to withdraw their consent at any time, including post-interview. Given the sensitive nature of the interview topic, it was important to ensure that participants were treated with respect at all times and that the risk of distress was minimised.

\section{Data collection}

The study commenced with the collection of qualitative data. Study participants formed a convenience sample of foster and kinship carers. They self-selected into the study by responding to advertisements distributed by several foster care agencies, including the peak bodies for foster and kinship carers in Victoria. Potential participants were informed that questions would relate to the mental health of children and young people for whom they had provided care or were currently caring. Thirty-one participants were involved - 14 kinship carers and 17 foster carers. Participants ranged in age from 32 to 74 years of age, living across greater metropolitan Melbourne. Six were male and 25 were female, and their caring experienced ranged from one to 21 years.

Focus groups are group discussions arranged to examine a specific set of topics (Kitzinger, 1994) with the aim of understanding the participants' meanings and interpretations at a deeper level than surveys or other methodologies may allow. This method gives researchers "a way of listening to 
people and learning from them" (Morgan, 1998). Twenty-eight carers took part in focus groups, divided by care type, and an additional three carers who could not attend but who wished to take part in the project were interviewed separately. The interviews and focus groups were semistructured, incorporating eight topic areas. These were introduced through questions on topics including the challenges participants faced in supporting children with their mental health needs and what support carers could access themselves in order to discharge this role. The interviews ranged from 30 to 45 minutes in length, while focus groups ranged from 90 to 120 minutes. Each session was facilitated by the lead author, and audio recordings were taken and transcribed.

\section{Data analysis}

Braun and Clarke (2006) identify a theme as capturing "something important about the data in relation to the research question" and state that it "represents some level of patterned response or meaning within the data set". Themes here were generated across the data set based on the strength of engagement among participants, including the number of different participants who articulated a theme and the number of individual occurrences of the theme across the data. Where an individual response provided a unique perspective, it has been included for contrast. Braun and Clarke (2006) describe six phases of thematic analysis, which were followed here. These are familiarisation with the data, generating initial codes, searching for themes, reviewing themes, defining and naming themes, and producing the report.

\section{Results}

Four themes, or categories, were defined and named through this methodology and were labelled as:

- "Day-to-to-day challenges": defining good mental health;

- "They just need to be kids": identity, shame, stigma, and a normal life;

- "The best interests of the child": partnerships, problems and solutions;

- "Pseudo-support systems": definitions of support. 
There are of course aspects of participants' responses that overlap across these categories.

\section{“Day-to-day challenges": defining good mental health}

This theme covers participants' understandings of what constitutes good mental health, and their view of mental health promotion and what children and young people need to develop and maintain good mental health. These perceptions appeared to be influenced by experiences of poor mental health and conditions leading to poor mental health, either in themselves, their families or among children and young people in their care. Most participants were able to provide a working definition of mental health. These definitions were diverse, and not all aligned with accepted professional definitions. Several participants were clearly relating their definition of mental health to specific issues they had faced with a child or young person in their care.

" "It is about the entire person and their ability to function well and manage well the day-to-day challenges that life may bring." (Female kinship carer)

"I guess it means that you are able to be responsible and live a productive life." (Male kinship carer)

“...different ways that these children process things, and how they react to the situation." (Female foster carer)

Overall, participants demonstrated an understanding of mental health as key to what some termed the "whole" or "entire" child, affecting their ability to cope with life's ups and downs, and identified a range of mental disorders that may have an impact on children in care. There was an implicit understanding among participants throughout the interviews that a carer's mental health and wellbeing was intrinsically linked to that of children in their care. Some carers explicitly stated concerns about what would happen if one day they couldn't cope or recounted stories of times when they felt they simply couldn't manage anymore, emphasising the importance of being able to maintain optimal conditions for their own good mental health in order to provide the same for the children in their care. Grandparent carers in particular were concerned about their health and resilience, with one participant questioning whether they could "keep up" with the demands of meeting the needs of their grandchildren. A sense of guilt at not being able to provide what a 
younger, more energetic parent might be able to provide pervaded some interviews.

“If I go down, she goes down, if you know what I mean..." (Female kinship carer)

"In some of the really dark moments...I've cried out, what do I do here?" (Female kinship carer)

"The relentlessness of parenting that I think all parents experience - the 24/7 thing - is just harder if you're old or if you have health issues." (Female kinship carer)

Participants unanimously reported their belief that the children in their care had more intensive mental health needs than children who were not subject to care and protection orders. Most carers seemed to recognise that these needs ebbed and flowed: often higher during stressful transitional phases such as placement change or puberty; and, heavily impacted by contact with birth parents or the birth of new siblings. While clearly focusing on the needs of the children in their care, participants understood that mental health was a major issue across the cohort in out-of-home care. Foster carers in particular felt that it was the norm for children in care to have problems with their mental health. Their exposure to a range of children in care over time provided many foster carers with the experience with which to make this assertion.

“...just about every child that comes in to your care, regardless of whatever trauma they've ever suffered, they're constantly working in that flight or fight mode." (Female foster carer)

There was a pervasive sense that the authorities, primarily child protection staff of the Department of Health and Human Services (DHHS), minimised the needs of children and young people, particularly when it came to mental health, and that there was not a recognition of the adverse conditions they experienced. Some participants recounted their experiences of being what one termed "put in their place" by DHHS staff, or being told they had it easy compared to other carers. Kinship carers in particular felt that their concerns were not taken seriously, possibly because for the most part they were not viewed as really part of what some described as "the system" in the same way as foster carers.

"I've been told well you know there are kids a lot worse than that, and oh we wouldn't be worried about that. If you had a child in the normal system and that was happening you'd be going hey there's something really wrong here, but she doesn't make the grade on the DHS system." (Male kinship carer) 
Kinship carers had a much better understanding than foster carers of potential intergenerational health problems, given their relationship with children's birth families. Most participants seemed aware that when parents had lived experience of mental health problems the chances were greater of similar problems in their children, some making reference to genetics, and others making reference to a history of problems in the family. When participants had at least basic knowledge about mental health problems in the child's parents it often led to them proactively seeking help through early intervention and prevention.

"I'm aware that it's there...genetic inheritance from her grandmother. Obviously if there was any indication of that I'd be up for getting it treated pretty damn quickly.” (Female kinship carer)

“Her mum has bi-polar. So I guess there's an awareness, gosh, I hope it's not genetic.” (Female kinship carer)

Almost all participants specifically referred to early intervention and prevention being extremely important to the promotion of good mental health. Many self-identified policing for early signs of any mental health disturbance in the children in their care, and actively taking a role in mental health promotion. However, participants universally felt that what many described as "the system" did not support them in their efforts to head off problems early. One kinship grandparent carer, speaking strongly in favour of mental health promotion and early intervention, even highlighted a lack of support in identifying mental health concerns when they were parenting their own child, the parent of the child in care.

"Now, had we been assisted as parents, even, into identifying the needs of this young person more fully before the crisis happened, then a lot of things could have been avoided that have ended up taking the Government a lot of money to help to rectify, by funding this child away from the parents..." (Female kinship carer)

“...for me it's all about prevention. It's about trying to identify how things could be difficult for her.” (Female kinship carer)

"It seems to me that it's more about management by crisis, instead of nipping it in the bud..." (Female foster carer)

This article is protected by copyright. All rights reserved. 


\section{"They just need to be kids": identity, shame, stigma, and a normal life}

Kinship carers in particular spoke at length about the various issues confronting children's parents and how these impacted upon the child's mental health and wellbeing. One kinship grandparent carer told the story of being pressured to say that she was her granddaughter's mother "so that she doesn't have any stigma". Others referred to a "family secret" and "dirty laundry". There was an overriding sense of despair among kinship grandparent carers and, for some, embarrassment about their children, the birth parents. Many carers spoke in detail about the care they took in helping destigmatise the care experience in order to help the children in their care feel as normal as possible. “...there's a shame element actually. I think that can really lead, well potentially to mental health issues in kids...” (Female kinship carer)

“I've simply said next year...we won't be able to take her out of school for access so we'll have to do it after school...I think that just makes kids feel more different and it's when kids feel extremely different that [there is] a potential for mental health issues." (Female foster carer)

"These kids...need to live as normal lives as possible, without being reminded all the time of the different issues that they [are] facing or living in or being subject to...they need just to be kids too." (Male kinship carer)

A significant factor contributing to this feeling of otherness among some children lay in their sometimes limited capacity to form and maintain friendships, and the resultant social isolation. Social connectedness is an important aspect of mental health promotion, and participants gave evidence of the constraints on the development of friendships at both a systemic and personal level, and highlighted the importance of positive friendships to children in care. Some participants, particularly kinship carers, stated that their own social situation suffered once they become carers, potentially resulting in further isolation of the new family unit.

“...they'll have an argument with their friends and they don't react the way the other children might react." (Female kinship carer)

“I don't think their history and...the system helps either, because they've often had many schools... when you go to the same primary school for 7 years you have friends..." (Female foster carer) 
“...I think there can be a lot of social isolation when you're a grandparent raising a grandchild. I mean my peers are all going overseas and going out to lunch.” (Female kinship carer)

Many children in the mainstream, particularly in their earlier years, rely on their parents to provide opportunities for positive social interaction, but kinship grandparent carers often have limited ageappropriate avenues available. Many participants felt that children benefited from interactions with peers who could reflect back their own experience and help them to establish their personal narrative. As children grow older and think more about their identity they may challenge their carers and take ownership over key decisions relating to identity.

"[It's] very important for them to have the people that are in exactly the same situation as themselves." (Female foster carer)

"I wonder about like we might be at a support group, but our kids aren't, you know? Kids with...illnesses often get to go on a camp together and things like that...” (Female kinship carer) "We were having a conversation the other night and they've both got very angry and are very frustrated with the term foster child...the oldest one now is saying to me 'I don't want you to sign my school forms anymore', and I said to her 'why sweetie', and she said 'because you have to put foster carer'." (Female foster carer)

It is clear there are many challenges in developing a narrative which forms the basis of a positive sense of self-identity for children in care, an important component in promoting mental health. Participants spoke about parents who were incarcerated, addicted to alcohol and other drugs, in violent and abusive relationships, and engaged in sex work. An additional complicating factor for younger children in particular, who are less likely to have an established attachment relationship to their parents, is trying to understand what one participant described as "what it all means".

"I think the kids need - and the carers - both of them need to perhaps have help to find a narrative that they're comfortable with as to why they're different." (Female kinship carer)

"I think the group that we're talking about...it's very hard for some of these children to process the fact that they've got Mum and Dad there, but then they've got their carers, and that can be very conflicting for them....tends to put their state of mental health into a different dimension again." (Female foster carer) 


\section{“The best interests of the child": the system, partnerships, problems and solutions}

The majority of foster carers $(n=11)$ and all kinship carers who participated said that they were inadequately informed on how to navigate what many described as "the system" upon commencing their caring role, and most still felt that they had little understanding of the resources available and how to access them, limiting their capacity to promote positive mental health. This theme was particularly strong amongst kinship carers. Carers suggested a range of potential solutions to help them and their peers better navigate what they described as "the system", many of them very practical. However, some of the suggested tools and aids, such as a carer handbook, already exist, highlighting the importance of informed, available case workers and support staff who can direct carers to the tools they need. This may be particularly critical for kinship carers, who stated more often than not that they had no case work support at all.

"I'm still, after ten years of being a grandparent carer, ignorant of what is available for [her]." (Female kinship carer)

"We haven't had [the Department of Health and Human Services] contact us except for [a] once a year letter. Probably [for] six, seven, eight years.” (Male kinship carer)

"People are entitled to different things, but you don't know until you ask, you've got no idea." (Female foster carer)

“...just really basic things...that would help you assist in caring for the child, holistically... what you can do, where you can go, what supports you're entitled to, reimbursements so that you're able to...not worry about finances...” (Female kinship carer)

The results of this study demonstrate that even when carers do have someone to ask for assistance or resources, there is a lack of consistency as to what is provided, even when carers are entitled to support. Participants also stated that they lacked the assistance necessary to access support. Many highlighted the inconsistency or inaccessibility of casework staff.

“We've got one child who is 16, she's been with us since she was a few months old, one who's 12 and he's been with us since he was only a few months old, and for that whole period we've received the carer payment for the younger one, but only for a short period of time for the older one." (Male 
kinship carer)

“You can go through three or four workers in two months." (Female foster carer)

"The changeover is an issue...children need routine, they need things that are predictable and they need to feel important and safe...we're within a system that doesn't actually promote that in children." (Female foster carer)

The high turnover of Child Protection staff in particular seems to limit the capacity of carers and caseworkers to build trusting, productive relationships in the best interests of the child. Many participants described instances of being ignored, criticised or being branded a troublemaker by DHHS staff when trying to advocate for the mental health needs of children in their care. In particular, participants described contact with birth parents as highly emotional for children, identifying careful management of contact as extremely important in promoting mental health. Proper management of contact was described as hindered by poor planning, poor coordination, a lack of support for children and carers, and a perceived bias towards the wishes of birth parents as opposed to the wishes of children in care.

“...you're actually trying to do anything that's in the best interests of the child...DHHS disagree with it, you're automatically hostile... whether you're actually correct or not, they don't care...they often won't answer the phone to you..." (Female kinship carer)

“...you're not allowed to ask DHHS questions, you're not allowed to have a right of reply with them..." (Male kinship carer)

"... [the mother had] recently abducted the child and the child was terrified of her. I had no way to say that this child is not ready [for contact]... when I actually went and got a medical opinion from our local doctor, [DHHS] threatened to take the doctor to court to override his decision for her to be sick for the day, and not attend access." (Female kinship carer)

\section{“Pseudo-support systems": definitions of support}

Almost all participants reported that they had not received adequate support to promote mental health or provide for the mental health needs of the children in their care. Even when carers identified an effective source of support they had been able to access, the positive impact was undermined by inadequate support and communication from key decision-makers, including the 
Department of Health and Human Services. Some participants detailed cases where DHHS had actively been a roadblock to promoting mental health or accessing appropriate support, even when that support had been independently sourced.

"...in order to give the child the best chance of staying mentally healthy or getting there, the carer needs tremendous support, and I haven't had it." (Female kinship carer)

“They're...pseudo support systems, they don't really exist, you can't get help.” (Female foster carer)

"She really is in need of counselling...the school psychologist has wanted to see this little girl, needing consent from the parents...I contacted [DHHS] to say you can override parents' decision if it's in the best interests of the child...it's been a real barrier, still haven't got consent from either parent or [DHHS] for this child to have counselling." (Female kinship carer)

An overwhelming sense of exasperation and, almost, despair about the caring experience was conveyed by many foster and kinship carers. Their comments indicate that while many carers are raising their hands to ask for time off to recharge their batteries, they are unable to access respite, often even in times of crisis. Carers identify respite as a potentially valuable link to other carers, facilitating informal peer support and decreasing their sense of isolation. Some carers also spoke positively of more formal peer support programs. However, one carer held an alternative perspective about accessing formal peer support, preferring to seek support from people in their own support network who were external to the care system.

“There is no support, like you can't go and say 'I want a night out', you can't just ring up a babysitter, because you've got to get it approved by [DHHS], and there is no facility really to get out and to have a break." (Female kinship carer)

"I think the greatest support we can have is each other." (Female foster carer)

"I'm glad I'm not alone out there drowning, that's what it feels like." (Female kinship carer)

\section{Discussion}

The results of this study suggest that both foster and kinship carers promote good mental health, consistent with the relevant literature (Fergeus et al, 2017; York \& Jones, 2017). Carers describe 
the experience of trying to shield or protect children from the worst impacts of their situation on their mental health, while trying to promote good mental health through their caring and the maintenance of a conducive living environment. Many carers clearly spoke about the importance of identifying where children may be at a high risk of developing mental illness or severe behavioural and development disturbances, and of making use of the opportunity provided by each child's removal from a negative situation and subsequent placement in out-of-home care to intervene early. Given their role as primary caregivers, foster and kinship carers play a critical day-to-day role in assisting children to feel as normal as possible (Single, 2005; McClung, 2007), in contrast with the sense of otherness many of the carers in this study recognised in the children in their care. Kinship carers have an advantage here, often having a far greater understanding of the child's birth parents, intergenerational health issues, and family history (Department of Communities, 2011). Conversely, the close relationship between most kinship carers and parents can create difficulties in itself as children and carers both try to manage competing and often conflicting loyalties (Breman, 2014). Both groups of carers identified their role in assisting children to develop a personal narrative that helps them to feel more secure in their identity and maintain a sense of wellbeing. This role may be of particular importance when it comes to contact with birth parents, as there is evidence that the way this contact is managed may affect the mental health of children in care (Jivanjee, 1999).

Both foster and kinship carers reported that they felt poorly equipped and had little support in promoting mental health and responding to the needs of the children in their care, although kinship carers were more likely to express this view. In many instances support was not offered at all, even when children were already clearly displaying signs of poor mental health. Where formal supports were in place, these had mostly been sought out and accessed by the carer with great difficulty. Indeed, most participants claimed that the Department of Health and Human Services (DHHS) disregarded or minimised the mental health needs of children. A number of participants expressed a view that the DHHS staff were more of a hindrance than a help in gaining access to appropriate mental health services and indeed at times created adverse conditions for the maintenance of good mental health.

The level of support available to different carers with similar levels of need appears inconsistent. 
This indicates that while services are available there are also barriers to accessing them when required, and that the systems designed to provide access are neither consistent nor transparent. Kinship carers were more likely to identify inadequate levels of support, although most foster carers also identified an inability to navigate what many participants described as "the system" effectively, particularly when beginning their caring role. This suggests that foster carer training and induction processes are insufficient to furnish new carers with the knowledge required to fulfil their role and to promote good mental health, while the majority of kinship carers receive no training at all. It also suggests that support staff are either too busy or lack the knowledge, skills and attitudes to help carers promote good mental health or to gain access to the services required to treat mental illness when needed. Carers should be provided with timely, accurate information in a consistent and respectful manner in order to assist them in navigating the service system and accessing appropriate services for the children in their care as and when they are required.

Carers, particularly kinship carers, reported their belief in a strong relationship between their own mental health and wellbeing and that of the children in their care, an issue raised powerfully by Dozier et al. (2002) and one which continues to be relevant. Dozier et al (2002) found that practical, psychological and emotional support for foster carers becomes critical for promoting mental health in infants in care. This finding is supported by carers in this study, across all age groups, and is also likely to be the case for kinship carers. In order to effectively fulfil their role in mental health promotion for the children in their care, foster and kinship carers should be provided with a level of support which allows them to maintain good personal health mental health. Formal peer support is identified as immensely valuable by some carers, but should be offered as part of a suite of support options including flexible respite care, responsive and accessible casework staff, and access to appropriate resources and specialist professionals.

Children in foster and kinship care are more likely to experience mental health problems than their mainstream peers (Milburn et al, 2008; Ford et al, 2011). The quality of care children receive in foster care is a major factor in the type of relationship they develop with their carer, and their time in care provides an opportunity to provide evidence-based interventions that have the potential to significantly improve their long-term psychological adjustment (Troutman, 2011). It is therefore vital that we understand the capacity of foster and kinship carers to support these children by promoting positive mental health, and to understand and respond more effectively to sometimes 
extremely complex mental health needs.

It can be argued that through placing children in out-of-home care the state has created an opportunity to prevent mental illness and provide effective early intervention to minimise its impact among a highly vulnerable group who otherwise may continue to experience a range of extremely adverse conditions such as exposure to abuse, neglect, instability, and violence. However, carers interviewed as part of this study clearly state that while many of these adverse conditions have been removed or their impact reduced by entry to care, they have been replaced by a range of new conditions which are also likely to have a serious and detrimental impact on the mental health and wellbeing of the children in their care.

\section{Limitations}

Convenience sampling was used to select participants, who indicated their interest in the study by responding to a callout for participants which was issued in several forms online. Potential participants who did not have internet access would have been unlikely to have seen the callout. Carers are not paid in Victoria, and time may have been a factor which prohibited the involvement of some carers who were also engaged in paid employment. Carers with an understanding of the importance of mental health were perhaps more likely to respond to the call for participants due to their interest in the subject. It should be noted that participants in this study represent a small sample of active carers in Victoria. Results should be read with this in mind.

\section{Conclusion}

This paper has explored the role of the carer in promoting the mental health of children in foster and kinship care through the examination of data collected through focus groups and interviews held with foster and kinship carers. Carers demonstrated a practical understanding of mental health and are able to identify a range of conditions that have an adverse impact on the mental health of the children in their care. Overwhelmingly, it seems that carers are proactively participating in mental health promotion, attempting to mitigate risk and strengthen protective factors. However, there is a lack of systemic support for carers, and even a range of barriers that affect their ability to promote the mental health and wellbeing of the children in their care. There is a need for improved access to mental health services for children in care, better resourcing for foster and kinship carers, 
availability of flexible respite care, the provision of timely and accurate information to carers, and targeted training and advice provided to carers on promoting mental health in vulnerable children.

This article is protected by copyright. All rights reserved. 


\section{References}

Braun, V. \& Clarke, V. (2006). Using thematic analysis in psychology. Qualitative Research in Psychology, 3 (2), 77-101.

Breman, R. (2014). Peeling back the layers: kinship care in Victoria. Melbourne: OzChild.

Department of Communities. (2011). Kinship care: a literature review. Brisbane: Department of Communities.

Department of Health. (2011). National mental health reform. Canberra: Department of Health.

Department of Health \& Human Services. (2017). Early intervention in mental health. Melbourne: Department of Health \& Human Services.

Development Service Group Inc., \& Child Information Welfare Gateway. (2015). Promoting protective factors for children and youth in foster care: a guide for practitioners. Washington, DC: U.S. Department of Health and Human Services.

Dozier, M., Higley, E., Albus, K. \& Nutter, A. (2002). Intervening with foster infant's caregivers: targeting three critical needs. Infants Mental Health Journal, 23, 541-554.

Farmer, E.M.Z, Burns, B.J, Chapman, M.V, Phillips, S.D, Angold, A, \& Costello, E.J. (2001). Use of mental health services by youth in contact with social services. Social Services Review, 75, 605624.

Fergeus, J., Humphreys, C., Harvey C., \& Herrman, H. (2017). Assisting carers to respond to the mental health needs of children. Children Australia, 42(1), 30-37.

Ford, T, Vostanis, P, Meltzer, H, \& Goodman, R. (2007). Psychiatric disorder among British children looked after by Local Authorities: comparison with children living in private households. British Journal of Psychiatry, 190, 319-325.

Herrman, H., Shekhar, S., \& Moodie, R. (eds). (2005). Promoting mental health: concepts, emerging evidence, practice: report of the World Health Organisation. Geneva: World Health Organisation.

Jivanjee, P. (1999). Professional and provider perspectives on family involvement in therapeutic foster care. Journal of Child and Family Studies, 8(3), 329-341.

Kitzinger, J. (1994). The methodology of focus groups: the importance of interaction between research participants. Sociology of Health and Illness, 16(1), 103-121.

McClung, L. (2007). Therapeutic foster care: integrating mental health and child welfare to provide care for traumatised children. Melbourne: Berry Street.

This article is protected by copyright. All rights reserved. 
Milburn, N.L, Lynch, M, \& Jackson, J. (2008). Early identification of mental health needs for children in care. Journal of Clinical Child Psychology and Psychiatry, 13(1), 31-47.

Minnis, H., \& Del Priore, C. (2001). Mental health services for looked after children: implications from two studies. Journal of Adoption and Fostering, 25, 27-38.

Morgan, D.L. (1998). The focus group guidebook. Thousand Oaks, California: Sage Publications.

Single, T. (2005). Long-term foster care for abused and neglected children: how foster parents can help in healing the trauma. Newcastle, New South Wales: John Hunter Children's Hospital.

Tarren-Sweeney, M. (2010). Concordance of mental health impairment and service utilisation among children in care. Journal of Clinical Child Psychology and Psychiatry, 15, 481-495.

Tarren-Sweeney, M, \& Vetere, A. (eds.) (2013). Mental health services for vulnerable children and young people. London: Routledge.

Troutman, B. (2011). The effects of foster care placement on young children's mental health: risks and opportunities. Iowa City: University of Iowa Carver College of Medicine.

Walker, L, Verins, I, Moodie, R, \& Webster, K in Herrman, H, Shekhar, S, \& Moodie, R. (eds.) (2005). Promoting mental health: concepts, emerging evidence, practice: report of the World Health Organisation. Geneva: World Health Organisation.

World Health Organisation. (2016). Mental health: strengthening our response. Geneva: World Health Organisation

York, W, \& Jones, J. (2017). Addressing the mental health needs of looked after children in foster care: the experiences of foster carers. Journal of Psychiatric and Mental Health Nursing, 24, 143153. 


\begin{abstract}
The majority of children and young people removed from the care of their parents by the State of Victoria, Australia, reside in foster or kinship care. These children have experienced a broad range of adverse conditions, and are up to four times more likely to experience problems with mental health than their mainstream peers. This paper draws on the perspectives of foster and kinship carers, describing the disconnection between their role as mental health advocates and their interest in early intervention in a field which is dominated by crisis and the historic marginalisation of foster and kinship carers. Thirty-one foster and kinship carers across greater metropolitan Melbourne, Australia, contributed to this study through interviews and focus groups. Participants demonstrated a practical understanding of mental health and an ability to identify a range of conditions that have an adverse impact on the mental health of children and young people in their care. The paper concludes that there is a lack of systemic support and even a range of barriers that affect the capacity of foster and kinship carers to promote the mental health and wellbeing of the children and young people in their care.
\end{abstract}

\title{
Keywords
}

Foster care; kinship care; mental health; carers; looked-after children; out-of-home care

\section{Background}

This paper draws on the perspectives of foster and kinship carers to examine their relationship with the mental health of children and young people in their care. It points to the disconnection between their role as mental health advocates and their interest in early intervention in a field which is dominated by crisis and the historic marginalisation of foster and kinship carers in out-of-home care services. In this paper, foster care is understood as the temporary care of children by accredited voluntary carers, while kinship care is the care provided by relatives or a member of a child's social network when a child cannot live with their parents. In Victoria, Australia, foster care and some kinship care services are delivered by community service organisations, commissioned by the Department of Health and Human Services, which regulates and oversees the out-of-home care system.

Mental health is the foundation for wellbeing and effective functioning for an individual and for a community (AUTHOR'S OWN). It is “a state of wellbeing in which the individual realises his or her own abilities, can cope with the normal stresses of life, can work productively and fruitfully, and is able to make a contribution to his or her community" (World Health Organisation, 2016). Conversely, mental illness may cause considerable suffering or hinder an individual's ability to care 
for themselves and function effectively in day-to-day life. In addition to genetic predisposition, adverse conditions such as poverty, low levels of education, unemployment, exposure to conflict, social marginalisation and displacement are likely to compromise mental health and cause serious risk of mental illness (AUTHOR'S OWN).

The greatest opportunity to prevent mental illness and provide effective early intervention to minimise its impact - which may otherwise have profound, long-term consequences - occurs during childhood. A lack of treatment in childhood may significantly increase the social and economic costs to the individual and the state later in life, a fact which has been recognised by both the Australian and Victorian Governments (Department of Health, 2011; Department of Health and Human Services, 2017). Such early intervention should include the identification of infants or children at higher risk of developing mental illness or severe behavioural and developmental disturbances, and the targeted promotion of mental health among these groups, including those in foster and kinship care.

Children in foster and kinship care are more likely to experience mental health problems than their mainstream peers (AUTHOR'S OWN). Children in out-of-home care in Australia are likely to have experienced a broad range of adverse conditions, and are up to four times more likely to experience problems with mental health than their mainstream peers (Milburn et al, 2008). Further, TarrenSweeney and Vetere (2013) claim that more than half of such children in the developed world have a measurable need for mental health services. The World Health Organisation argues that promoting mental health needs to be assigned a higher priority in vulnerable groups (AUTHOR'S OWN). Given their level of vulnerability, the promotion of mental health amongst children in foster and kinship care should therefore be of the highest priority.

Foster and kinship carers provide a critical role in the lives of children in care. The knowledge, skills and resources possessed by carers can be pivotal in connecting youth to appropriate mental health services (Farmer et al, 2001). Conversely, Tarren-Sweeney (2010) found that carers without the requisite knowledge, skills or interest could be a barrier to accessing critical mental health services. Supportive relationships, such as those provided by foster and kinship carers, are considered to be a key determinant of children's mental health (Walker et al, 2005), and in recent years, there has been significant progress in identifying interventions that improve the ability of foster carers to respond to the mental health needs of children in their care (AUTHOR'S OWN).

When it comes to children in care, carers have emerged as powerful drivers of access to various forms of health care in a number of studies, and they can be an important agent of change when it comes to improving their child's emotional well-being, due to their expertise in understanding the 
individual child (AUTHOR'S OWN; Minnis \& Del Priore, 2001). Given that the uptake of mental health services for children in care is relatively low (York \& Jones, 2017), this represents a critical contribution. The quality of day-to-day care that children receive from foster and kinship carers and the nature of the caring environment are major factors influencing their mental health and wellbeing. Carers are likely to be the key to effective mental health promotion among children and young people in foster and kinship care. They may support increased social connectedness and the development of problem-solving skills, nurturing and providing empathetic care, and are key to lessening the impact of the multiple risk factors which can affect children in care (Development Services Group, 2015). It is therefore important to better understand carers' role in mental health promotion, their perspectives on mental health, and the support they receive in promoting mental health through their role in providing therapeutic caring environments for children and young people. This paper will examine two key questions:

- what is the role of the carer in promoting the mental health of vulnerable children in foster and kinship care?

- how can carers be supported to fulfil this role?

\section{Method and Theoretical Framework}

REDACTED FOR REVIEW. The study utilised thematic analysis to develop an understanding of the role of the carer in promoting the mental health of children and young people in foster and kinship care. To this end, the study design incorporates the use of semi-structured interviews and focus groups with foster and kinship carers providing care to children across Victoria.

\section{Ethics}

REDACTED FOR REVIEW. Additional approval was provided by the Department of Human Services Research Coordinating Committee, and the relevant committees of participating community service organisations. Participants opted in to participation in the study, and were free to withdraw their consent at any time, including post-interview. Given the sensitive nature of the interview topic, it was important to ensure that participants were treated with respect at all times and that the risk of distress was minimised.

\section{Data collection}

The study commenced with the collection of qualitative data. Study participants formed a convenience sample of foster and kinship carers. They self-selected into the study by responding to 
advertisements distributed by several foster care agencies, including the peak bodies for foster and kinship carers in Victoria. Potential participants were informed that questions would relate to the mental health of children and young people for whom they had provided care or were currently caring. Thirty-one participants were involved - 14 kinship carers and 17 foster carers. Participants ranged in age from 32 to 74 years of age, living across greater metropolitan Melbourne. Six were male and 25 were female, and their caring experienced ranged from one to 21 years.

Focus groups are group discussions arranged to examine a specific set of topics (Kitzinger, 1994) with the aim of understanding the participants' meanings and interpretations at a deeper level than surveys or other methodologies may allow. This method gives researchers "a way of listening to people and learning from them" (Morgan, 1998). Twenty-eight carers took part in focus groups, divided by care type, and an additional three carers who could not attend but who wished to take part in the project were interviewed separately. The interviews and focus groups were semistructured, incorporating eight topic areas. These were introduced through questions on topics including the challenges participants faced in supporting children with their mental health needs and what support carers could access themselves in order to discharge this role. The interviews ranged from 30 to 45 minutes in length, while focus groups ranged from 90 to 120 minutes. Each session was facilitated by the lead author, and audio recordings were taken and transcribed.

\section{Data analysis}

Braun and Clarke (2006) identify a theme as capturing "something important about the data in relation to the research question" and state that it "represents some level of patterned response or meaning within the data set". Themes here were generated across the data set based on the strength of engagement among participants, including the number of different participants who articulated a theme and the number of individual occurrences of the theme across the data. Where an individual response provided a unique perspective, it has been included for contrast. Braun and Clarke (2006) describe six phases of thematic analysis, which were followed here. These are familiarisation with the data, generating initial codes, searching for themes, reviewing themes, defining and naming themes, and producing the report.

\section{Results}

Four themes, or categories, were defined and named through this methodology and were labelled as:

- "Day-to-to-day challenges": defining good mental health; 
- "They just need to be kids": identity, shame, stigma, and a normal life;

- "The best interests of the child": partnerships, problems and solutions;

- "Pseudo-support systems": definitions of support.

There are of course aspects of participants' responses that overlap across these categories.

\section{“Day-to-day challenges": defining good mental health}

This theme covers participants' understandings of what constitutes good mental health, and their view of mental health promotion and what children and young people need to develop and maintain good mental health. These perceptions appeared to be influenced by experiences of poor mental health and conditions leading to poor mental health, either in themselves, their families or among children and young people in their care. Most participants were able to provide a working definition of mental health. These definitions were diverse, and not all aligned with accepted professional definitions. Several participants were clearly relating their definition of mental health to specific issues they had faced with a child or young person in their care.

"It is about the entire person and their ability to function well and manage well the day-to-day challenges that life may bring." (Female kinship carer)

"I guess it means that you are able to be responsible and live a productive life." (Male kinship carer)

“...different ways that these children process things, and how they react to the situation." (Female foster carer)

Overall, participants demonstrated an understanding of mental health as key to what some termed the "whole" or "entire" child, affecting their ability to cope with life's ups and downs, and identified a range of mental disorders that may have an impact on children in care. There was an implicit understanding among participants throughout the interviews that a carer's mental health and wellbeing was intrinsically linked to that of children in their care. Some carers explicitly stated concerns about what would happen if one day they couldn't cope or recounted stories of times when they felt they simply couldn't manage anymore, emphasising the importance of being able to maintain optimal conditions for their own good mental health in order to provide the same for the children in their care. Grandparent carers in particular were concerned about their health and resilience, with one participant questioning whether they could "keep up" with the demands of meeting the needs of their grandchildren. A sense of guilt at not being able to provide what a 
younger, more energetic parent might be able to provide pervaded some interviews.

“If I go down, she goes down, if you know what I mean...” (Female kinship carer)

“In some of the really dark moments...I've cried out, what do I do here?” (Female kinship carer)

"The relentlessness of parenting that I think all parents experience - the 24/7 thing - is just harder if you're old or if you have health issues." (Female kinship carer)

Participants unanimously reported their belief that the children in their care had more intensive mental health needs than children who were not subject to care and protection orders. Most carers seemed to recognise that these needs ebbed and flowed: often higher during stressful transitional phases such as placement change or puberty; and, heavily impacted by contact with birth parents or the birth of new siblings. While clearly focusing on the needs of the children in their care, participants understood that mental health was a major issue across the cohort in out-of-home care. Foster carers in particular felt that it was the norm for children in care to have problems with their mental health. Their exposure to a range of children in care over time provided many foster carers with the experience with which to make this assertion.

“...just about every child that comes in to your care, regardless of whatever trauma they've ever suffered, they're constantly working in that flight or fight mode." (Female foster carer)

There was a pervasive sense that the authorities, primarily child protection staff of the Department of Health and Human Services (DHHS), minimised the needs of children and young people, particularly when it came to mental health, and that there was not a recognition of the adverse conditions they experienced. Some participants recounted their experiences of being what one termed "put in their place" by DHHS staff, or being told they had it easy compared to other carers. Kinship carers in particular felt that their concerns were not taken seriously, possibly because for the most part they were not viewed as really part of what some described as "the system" in the same way as foster carers.

"I've been told well you know there are kids a lot worse than that, and oh we wouldn't be worried about that. If you had a child in the normal system and that was happening you'd be going hey there's something really wrong here, but she doesn't make the grade on the DHS system." (Male kinship carer)

Kinship carers had a much better understanding than foster carers of potential intergenerational health problems, given their relationship with children's birth families. Most participants seemed aware that when parents had lived experience of mental health problems the chances were greater of similar problems in their children, some making reference to genetics, and others making reference to a history of problems in the family. When participants had at least basic knowledge about mental 
health problems in the child's parents it often led to them proactively seeking help through early intervention and prevention.

"I'm aware that it's there...genetic inheritance from her grandmother. Obviously if there was any indication of that I'd be up for getting it treated pretty damn quickly." (Female kinship carer)

“Her mum has bi-polar. So I guess there's an awareness, gosh, I hope it's not genetic." (Female kinship carer)

Almost all participants specifically referred to early intervention and prevention being extremely important to the promotion of good mental health. Many self-identified policing for early signs of any mental health disturbance in the children in their care, and actively taking a role in mental health promotion. However, participants universally felt that what many described as "the system" did not support them in their efforts to head off problems early. One kinship grandparent carer, speaking strongly in favour of mental health promotion and early intervention, even highlighted a lack of support in identifying mental health concerns when they were parenting their own child, the parent of the child in care.

"Now, had we been assisted as parents, even, into identifying the needs of this young person more fully before the crisis happened, then a lot of things could have been avoided that have ended up taking the Government a lot of money to help to rectify, by funding this child away from the parents...” (Female kinship carer)

“...for me it's all about prevention. It's about trying to identify how things could be difficult for her.” (Female kinship carer)

"It seems to me that it's more about management by crisis, instead of nipping it in the bud..." (Female foster carer)

\section{"They just need to be kids": identity, shame, stigma, and a normal life}

Kinship carers in particular spoke at length about the various issues confronting children's parents and how these impacted upon the child's mental health and wellbeing. One kinship grandparent carer told the story of being pressured to say that she was her granddaughter's mother "so that she doesn't have any stigma". Others referred to a "family secret" and "dirty laundry". There was an overriding sense of despair among kinship grandparent carers and, for some, embarrassment about their children, the birth parents. Many carers spoke in detail about the care they took in helping destigmatise the care experience in order to help the children in their care feel as normal as possible.

“...there's a shame element actually. I think that can really lead, well potentially to mental health 
issues in kids...” (Female kinship carer)

"I've simply said next year...we won't be able to take her out of school for access so we'll have to do it after school...I think that just makes kids feel more different and it's when kids feel extremely different that [there is] a potential for mental health issues." (Female foster carer)

"These kids...need to live as normal lives as possible, without being reminded all the time of the different issues that they [are] facing or living in or being subject to...they need just to be kids too." (Male kinship carer)

A significant factor contributing to this feeling of otherness among some children lay in their sometimes limited capacity to form and maintain friendships, and the resultant social isolation. Social connectedness is an important aspect of mental health promotion, and participants gave evidence of the constraints on the development of friendships at both a systemic and personal level, and highlighted the importance of positive friendships to children in care. Some participants, particularly kinship carers, stated that their own social situation suffered once they become carers, potentially resulting in further isolation of the new family unit.

“...they'll have an argument with their friends and they don't react the way the other children might react." (Female kinship carer)

“I don't think their history and...the system helps either, because they've often had many schools... when you go to the same primary school for 7 years you have friends..." (Female foster carer)

“...I think there can be a lot of social isolation when you're a grandparent raising a grandchild. I mean my peers are all going overseas and going out to lunch.” (Female kinship carer)

Many children in the mainstream, particularly in their earlier years, rely on their parents to provide opportunities for positive social interaction, but kinship grandparent carers often have limited ageappropriate avenues available. Many participants felt that children benefited from interactions with peers who could reflect back their own experience and help them to establish their personal narrative. As children grow older and think more about their identity they may challenge their carers and take ownership over key decisions relating to identity.

"[It's] very important for them to have the people that are in exactly the same situation as themselves." (Female foster carer)

"I wonder about like we might be at a support group, but our kids aren't, you know? Kids with...illnesses often get to go on a camp together and things like that...” (Female kinship carer)

“We were having a conversation the other night and they've both got very angry and are very 
frustrated with the term foster child...the oldest one now is saying to me 'I don't want you to sign my school forms anymore', and I said to her 'why sweetie', and she said 'because you have to put foster carer'." (Female foster carer)

It is clear there are many challenges in developing a narrative which forms the basis of a positive sense of self-identity for children in care, an important component in promoting mental health. Participants spoke about parents who were incarcerated, addicted to alcohol and other drugs, in violent and abusive relationships, and engaged in sex work. An additional complicating factor for younger children in particular, who are less likely to have an established attachment relationship to their parents, is trying to understand what one participant described as "what it all means".

"I think the kids need - and the carers - both of them need to perhaps have help to find a narrative that they're comfortable with as to why they're different." (Female kinship carer)

"I think the group that we're talking about...it's very hard for some of these children to process the fact that they've got Mum and Dad there, but then they've got their carers, and that can be very conflicting for them....tends to put their state of mental health into a different dimension again."

(Female foster carer)

\section{“The best interests of the child": the system, partnerships, problems and solutions}

The majority of foster carers $(n=11)$ and all kinship carers who participated said that they were inadequately informed on how to navigate what many described as "the system" upon commencing their caring role, and most still felt that they had little understanding of the resources available and how to access them, limiting their capacity to promote positive mental health. This theme was particularly strong amongst kinship carers. Carers suggested a range of potential solutions to help them and their peers better navigate what they described as "the system", many of them very practical. However, some of the suggested tools and aids, such as a carer handbook, already exist, highlighting the importance of informed, available case workers and support staff who can direct carers to the tools they need. This may be particularly critical for kinship carers, who stated more often than not that they had no case work support at all.

"I'm still, after ten years of being a grandparent carer, ignorant of what is available for [her]." (Female kinship carer)

"We haven't had [the Department of Health and Human Services] contact us except for [a] once a year letter. Probably [for] six, seven, eight years." (Male kinship carer)

"People are entitled to different things, but you don't know until you ask, you've got no idea." 
(Female foster carer)

“...just really basic things...that would help you assist in caring for the child, holistically... what you can do, where you can go, what supports you're entitled to, reimbursements so that you're able to...not worry about finances...” (Female kinship carer)

The results of this study demonstrate that even when carers do have someone to ask for assistance or resources, there is a lack of consistency as to what is provided, even when carers are entitled to support. Participants also stated that they lacked the assistance necessary to access support. Many highlighted the inconsistency or inaccessibility of casework staff.

“We've got one child who is 16, she's been with us since she was a few months old, one who's 12 and he's been with us since he was only a few months old, and for that whole period we've received the carer payment for the younger one, but only for a short period of time for the older one." (Male kinship carer)

“You can go through three or four workers in two months." (Female foster carer)

"The changeover is an issue...children need routine, they need things that are predictable and they need to feel important and safe...we're within a system that doesn't actually promote that in children." (Female foster carer)

The high turnover of Child Protection staff in particular seems to limit the capacity of carers and caseworkers to build trusting, productive relationships in the best interests of the child. Many participants described instances of being ignored, criticised or being branded a troublemaker by DHHS staff when trying to advocate for the mental health needs of children in their care. In particular, participants described contact with birth parents as highly emotional for children, identifying careful management of contact as extremely important in promoting mental health. Proper management of contact was described as hindered by poor planning, poor coordination, a lack of support for children and carers, and a perceived bias towards the wishes of birth parents as opposed to the wishes of children in care.

“...you're actually trying to do anything that's in the best interests of the child...DHHS disagree with it, you're automatically hostile... whether you're actually correct or not, they don't care...they often won't answer the phone to you...” (Female kinship carer)

“...you're not allowed to ask DHHS questions, you're not allowed to have a right of reply with them..." (Male kinship carer)

“...[the mother had] recently abducted the child and the child was terrified of her. I had no way to say that this child is not ready [for contact]... when I actually went and got a medical opinion from 
our local doctor, [DHHS] threatened to take the doctor to court to override his decision for her to be sick for the day, and not attend access." (Female kinship carer)

\section{“Pseudo-support systems": definitions of support}

Almost all participants reported that they had not received adequate support to promote mental health or provide for the mental health needs of the children in their care. Even when carers identified an effective source of support they had been able to access, the positive impact was undermined by inadequate support and communication from key decision-makers, including the Department of Health and Human Services. Some participants detailed cases where DHHS had actively been a roadblock to promoting mental health or accessing appropriate support, even when that support had been independently sourced.

"...in order to give the child the best chance of staying mentally healthy or getting there, the carer needs tremendous support, and I haven't had it." (Female kinship carer)

“They're...pseudo support systems, they don't really exist, you can't get help.” (Female foster carer)

"She really is in need of counselling...the school psychologist has wanted to see this little girl, needing consent from the parents...I contacted [DHHS] to say you can override parents' decision if it's in the best interests of the child...it's been a real barrier, still haven't got consent from either parent or [DHHS] for this child to have counselling.” (Female kinship carer)

An overwhelming sense of exasperation and, almost, despair about the caring experience was conveyed by many foster and kinship carers. Their comments indicate that while many carers are raising their hands to ask for time off to recharge their batteries, they are unable to access respite, often even in times of crisis. Carers identify respite as a potentially valuable link to other carers, facilitating informal peer support and decreasing their sense of isolation. Some carers also spoke positively of more formal peer support programs. However, one carer held an alternative perspective about accessing formal peer support, preferring to seek support from people in their own support network who were external to the care system.

“There is no support, like you can't go and say 'I want a night out', you can't just ring up a babysitter, because you've got to get it approved by [DHHS], and there is no facility really to get out and to have a break." (Female kinship carer)

"I think the greatest support we can have is each other." (Female foster carer)

“I'm glad I'm not alone out there drowning, that's what it feels like." (Female kinship carer) 


\section{Discussion}

The results of this study suggest that both foster and kinship carers promote good mental health, consistent with the relevant literature (AUTHOR'S OWN; York \& Jones, 2017). Carers describe the experience of trying to shield or protect children from the worst impacts of their situation on their mental health, while trying to promote good mental health through their caring and the maintenance of a conducive living environment. Many carers clearly spoke about the importance of identifying where children may be at a high risk of developing mental illness or severe behavioural and development disturbances, and of making use of the opportunity provided by each child's removal from a negative situation and subsequent placement in out-of-home care to intervene early.

Given their role as primary caregivers, foster and kinship carers play a critical day-to-day role in assisting children to feel as normal as possible (Single, 2005; McClung, 2007), in contrast with the sense of otherness many of the carers in this study recognised in the children in their care. Kinship carers have an advantage here, often having a far greater understanding of the child's birth parents, intergenerational health issues, and family history (Department of Communities, 2011).

Conversely, the close relationship between most kinship carers and parents can create difficulties in itself as children and carers both try to manage competing and often conflicting loyalties (Breman, 2014). Both groups of carers identified their role in assisting children to develop a personal narrative that helps them to feel more secure in their identity and maintain a sense of wellbeing. This role may be of particular importance when it comes to contact with birth parents, as there is evidence that the way this contact is managed may affect the mental health of children in care (Jivanjee, 1999).

Both foster and kinship carers reported that they felt poorly equipped and had little support in promoting mental health and responding to the needs of the children in their care, although kinship carers were more likely to express this view. In many instances support was not offered at all, even when children were already clearly displaying signs of poor mental health. Where formal supports were in place, these had mostly been sought out and accessed by the carer with great difficulty. Indeed, most participants claimed that the Department of Health and Human Services (DHHS) disregarded or minimised the mental health needs of children. A number of participants expressed a view that the DHHS staff were more of a hindrance than a help in gaining access to appropriate mental health services and indeed at times created adverse conditions for the maintenance of good mental health.

The level of support available to different carers with similar levels of need appears inconsistent. This indicates that while services are available there are also barriers to accessing them when required, and that the systems designed to provide access are neither consistent nor transparent. 
Kinship carers were more likely to identify inadequate levels of support, although most foster carers also identified an inability to navigate what many participants described as "the system" effectively, particularly when beginning their caring role. This suggests that foster carer training and induction processes are insufficient to furnish new carers with the knowledge required to fulfil their role and to promote good mental health, while the majority of kinship carers receive no training at all. It also suggests that support staff are either too busy or lack the knowledge, skills and attitudes to help carers promote good mental health or to gain access to the services required to treat mental illness when needed. Carers should be provided with timely, accurate information in a consistent and respectful manner in order to assist them in navigating the service system and accessing appropriate services for the children in their care as and when they are required.

Carers, particularly kinship carers, reported their belief in a strong relationship between their own mental health and wellbeing and that of the children in their care, an issue raised powerfully by Dozier et al. (2002) and one which continues to be relevant. Dozier et al (2002) found that practical, psychological and emotional support for foster carers becomes critical for promoting mental health in infants in care. This finding is supported by carers in this study, across all age groups, and is also likely to be the case for kinship carers. In order to effectively fulfil their role in mental health promotion for the children in their care, foster and kinship carers should be provided with a level of support which allows them to maintain good personal health mental health. Formal peer support is identified as immensely valuable by some carers, but should be offered as part of a suite of support options including flexible respite care, responsive and accessible casework staff, and access to appropriate resources and specialist professionals.

Children in foster and kinship care are more likely to experience mental health problems than their mainstream peers (Milburn et al, 2008; Ford et al, 2011). The quality of care children receive in foster care is a major factor in the type of relationship they develop with their carer, and their time in care provides an opportunity to provide evidence-based interventions that have the potential to significantly improve their long-term psychological adjustment (Troutman, 2011). It is therefore vital that we understand the capacity of foster and kinship carers to support these children by promoting positive mental health, and to understand and respond more effectively to sometimes extremely complex mental health needs.

It can be argued that through placing children in out-of-home care the state has created an opportunity to prevent mental illness and provide effective early intervention to minimise its impact among a highly vulnerable group who otherwise may continue to experience a range of extremely adverse conditions such as exposure to abuse, neglect, instability, and violence. However, carers interviewed as part of this study clearly state that while many of these adverse conditions have been 
removed or their impact reduced by entry to care, they have been replaced by a range of new conditions which are also likely to have a serious and detrimental impact on the mental health and wellbeing of the children in their care.

\section{Limitations}

Convenience sampling was used to select participants, who indicated their interest in the study by responding to a callout for participants which was issued in several forms online. Potential participants who did not have internet access would have been unlikely to have seen the callout. Carers are not paid in Victoria, and time may have been a factor which prohibited the involvement of some carers who were also engaged in paid employment. Carers with an understanding of the importance of mental health were perhaps more likely to respond to the call for participants due to their interest in the subject. It should be noted that participants in this study represent a small sample of active carers in Victoria. Results should be read with this in mind.

\section{Conclusion}

This paper has explored the role of the carer in promoting the mental health of children in foster and kinship care through the examination of data collected through focus groups and interviews held with foster and kinship carers. Carers demonstrated a practical understanding of mental health and are able to identify a range of conditions that have an adverse impact on the mental health of the children in their care. Overwhelmingly, it seems that carers are proactively participating in mental health promotion, attempting to mitigate risk and strengthen protective factors. However, there is a lack of systemic support for carers, and even a range of barriers that affect their ability to promote the mental health and wellbeing of the children in their care. There is a need for improved access to mental health services for children in care, better resourcing for foster and kinship carers, availability of flexible respite care, the provision of timely and accurate information to carers, and targeted training and advice provided to carers on promoting mental health in vulnerable children. 


\section{References (Author's own removed for review)}

Braun, V. \& Clarke, V. (2006). Using thematic analysis in psychology. Qualitative Research in Psychology, 3 (2), 77-101.

Breman, R. (2014). Peeling back the layers: kinship care in Victoria. Melbourne: OzChild.

Department of Communities. (2011). Kinship care: a literature review. Brisbane: Department of Communities.

Department of Health. (2011). National mental health reform. Canberra: Department of Health.

Department of Health \& Human Services. (2017). Early intervention in mental health. Melbourne: Department of Health \& Human Services.

Development Service Group Inc., \& Child Information Welfare Gateway. (2015). Promoting protective factors for children and youth in foster care: a guide for practitioners. Washington, DC: U.S. Department of Health and Human Services.

Dozier, M., Higley, E., Albus, K. \& Nutter, A. (2002). Intervening with foster infant's caregivers: targeting three critical needs. Infants Mental Health Journal, 23, 541-554.

Farmer, E.M.Z, Burns, B.J, Chapman, M.V, Phillips, S.D, Angold, A, \& Costello, E.J. (2001). Use of mental health services by youth in contact with social services. Social Services Review, 75, 605624.

Ford, T, Vostanis, P, Meltzer, H, \& Goodman, R. (2007). Psychiatric disorder among British children looked after by Local Authorities: comparison with children living in private households. British Journal of Psychiatry, 190, 319-325.

Jivanjee, P. (1999). Professional and provider perspectives on family involvement in therapeutic foster care. Journal of Child and Family Studies, 8(3), 329-341.

Kitzinger, J. (1994). The methodology of focus groups: the importance of interaction between research participants. Sociology of Health and Illness, 16(1), 103-121.

McClung, L. (2007). Therapeutic foster care: integrating mental health and child welfare to provide care for traumatised children. Melbourne: Berry Street.

Milburn, N.L, Lynch, M, \& Jackson, J. (2008). Early identification of mental health needs for children in care. Journal of Clinical Child Psychology and Psychiatry, 13(1), 31-47.

Minnis, H., \& Del Priore, C. (2001). Mental health services for looked after children: implications from two studies. Journal of Adoption and Fostering, 25, 27-38.

Morgan, D.L. (1998). The focus group guidebook. Thousand Oaks, California: Sage Publications.

Single, T. (2005). Long-term foster care for abused and neglected children: how foster parents can help in healing the trauma. Newcastle, New South Wales: John Hunter Children's Hospital.

Tarren-Sweeney, M. (2010). Concordance of mental health impairment and service utilisation among children in care. Journal of Clinical Child Psychology and Psychiatry, 15, 481-495. 
Tarren-Sweeney, M, \& Vetere, A. (eds.) (2013). Mental health services for vulnerable children and young people. London: Routledge.

Troutman, B. (2011). The effects of foster care placement on young children's mental health: risks and opportunities. Iowa City: University of Iowa Carver College of Medicine.

Walker, L, Verins, I, Moodie, R, \& Webster, K in Herrman, H, Shekhar, S, \& Moodie, R. (eds.) (2005). Promoting mental health: concepts, emerging evidence, practice: report of the World Health Organisation. Geneva: World Health Organisation.

World Health Organisation. (2016). Mental health: strengthening our response. Geneva: World Health Organisation

York, W, \& Jones, J. (2017). Addressing the mental health needs of looked after children in foster care: the experiences of foster carers. Journal of Psychiatric and Mental Health Nursing, 24, 143153. 


\section{University Library}

\section{- M M N E R VA A gateway to Melbourne's research publications}

Minerva Access is the Institutional Repository of The University of Melbourne

Author/s:

Fergeus, J;Humphreys, C;Harvey, C;Herrman, H

Title:

Supporting foster and kinship carers to promote the mental health of children

Date:

2019-02-01

Citation:

Fergeus, J., Humphreys, C., Harvey, C. \& Herrman, H. (2019). Supporting foster and kinship carers to promote the mental health of children. CHILD \& FAMILY SOCIAL WORK, 24 (1), pp.77-83. https://doi.org/10.1111/cfs. 12583.

Persistent Link:

http://hdl.handle.net/11343/284010 